\title{
The Association between Noncommercial Partnerships and Risk of HIV among Female Sex Workers: Evidences from a Cross-Sectional Behavioral and Biological Survey in Southern India
}

\author{
Renuka Pulikallu Somanath, ${ }^{1}$ Ram Manohar Mishra, ${ }^{2}$ \\ Niranjan Saggurti, ${ }^{2}$ and Prabhakar Parimi ${ }^{1}$ \\ ${ }^{1}$ India HIV/AIDS Alliance, Hyderabad 500063, Andhra Pradesh, India \\ ${ }^{2}$ HIV \& AIDS Program, Population Council, New Delhi 110003, India \\ Correspondence should be addressed to Ram Manohar Mishra; rammanohar7@yahoo.co.in
}

Received 6 September 2012; Accepted 30 January 2013

Academic Editor: P. K. Nicholas

Copyright (c) 2013 Renuka Pulikallu Somanath et al. This is an open access article distributed under the Creative Commons Attribution License, which permits unrestricted use, distribution, and reproduction in any medium, provided the original work is properly cited.

\begin{abstract}
This paper examines the association between female sex workers' (FSWs) noncommercial partnerships with risk of HIV in Andhra Pradesh, India. Data were drawn from a cross-sectional behavioral and biological survey conducted in 2009 among 3225 FSWs from Andhra Pradesh. Participants were asked about their sexual partnerships, condom use, and vulnerability factors and tested for HIV and sexually transmitted infections. The key independent variables considered were presence of a noncommercial sexual partner (no, yes) and the nature of such partnerships (regular, nonregular). FSWs who reported husband as noncommercial partner were considered to have a regular partner, while the rest were defined as having nonregular partners. Adjusted odds ratios (OR) and $95 \%$ confidence intervals (CI) were estimated to measure the associations between variables of interest. Almost three-fourths (74.8\%) of FSWs reported having noncommercial partners (regular: 55.6\%; nonregular: 19.3\%). FSWs in nonregular partnerships were more likely to be HIV positive ( $13.1 \%$ versus $10.9 \%$, adjusted OR: $1.4,95 \%$ CI: $1.1-1.8)$, have syphilis (10.3\% versus $4.2 \%$, adjusted OR: 2.3, 95\% CI: 1.6-3.3), use condoms inconsistently with occasional clients (21.0\% versus $16.5 \%$, adjusted OR: 1.5, 95\% CI: $1.2-1.9)$, and report forced sex (25.1\% versus $14.1 \%$, adjusted OR: $1.9,95 \%$ CI: $1.5-2.4)$ as compared to those in regular partnerships. HIV prevention programs need to emphasize safe sex behaviors, particularly among FSWs who have nonregular partners.
\end{abstract}

\section{Introduction}

Currently, there are about 2.4 million people living with HIV in India [1]. The HIV epidemic in the country is predominantly heterosexual and is assumed to be fuelled mainly through unprotected sex with female sex workers (FSWs) [2]. Although the country has witnessed a declining trend in the adult HIV prevalence rate, the HIV prevalence is substantially high among most at risk groups such as FSWs [1]. Indeed, HIV prevalence among FSWs in the country is about 15 times higher than in the low-risk general population $[3,4]$. Hence, HIV prevention programs in India continue to focus on the prevention of new HIV infections among FSWs and their sexual partners by promoting consistent condom use and treatment of sexually transmitted infections (STIs) in these groups [5].

While programmatic efforts across the country are believed to have resulted in higher levels of consistent condom use among FSWs with commercial sex partners [6-8], the consistent condom use practice remains at a much lower level with noncommercial partners such as husbands, boyfriends, pimps, and the police [9-11]. Due to low condom use, noncommercial partners have increasingly been recognized as a bridge group for targeted HIV prevention programs in India [9]; however, the effectiveness of interventions in increasing consistent condom use among noncommercial partners is not clear $[9,10,12,13]$. 
The role of noncommercial partnerships in determining FSW' vulnerability to HIV may be more complex and multidimensional than merely low condom use within such partnerships. For example, in a recent study, FSWs in southern India attributed their initiation of sex work and practice of high-risk behaviors (e.g., anal sex, inconsistent condom use in commercial sex) to increase financial debt being burdened by their noncommercial partners [14]. At the same time, many FSWs associated the departure of or abandonment by their husband to their economic hardship and subsequently to their initiation of sex work and practice of high risk behaviors [14]. Noncommercial sexual partners such as husbands, boyfriends, the police, and pimps were reported to act as protectors, as well as perpetrators of violence against FSWs in India $[15,16]$.

Studies have also shown that spousal sex has a positive effect on condom use in commercial sex among other highrisk population groups such as truckers. It has been noticed that married truckers were more likely to use condoms with nonmarital nonregular partners than their unmarried counterparts, possibly to protect themselves and their spouse from infection [17, 18]. Moreover, noncommercial relationships, especially with the husband, may have a positive effect on FSWs' sexual behavior, as they may result in less dependency on sex work (and hence less exposure to HIV and STI risk), safe sexual practices in commercial sex (e.g., consistent condom use), and psychosocial and physical protection from exogenous factors such as psychological harassment and physical and sexual violence. Thus, although many studies globally have documented the role of noncommercial partnerships in increasing FSWs' vulnerability to HIV mainly due to the low level of condom use within such relationships $[9,19-23]$, the differential effect of having husband or nonhusband as noncommercial partners received less attention in the literature, particularly in India. In this context, this study aims to examine the association between FSWs' noncommercial partnerships and their vulnerability to HIV in Andhra Pradesh, a southern state in India, with the highest burden of HIV in the country [1].

\section{Materials and Methods}

2.1. Data. We used data from a cross-sectional behavioral and biological survey among FSWs in eight districts of Andhra Pradesh. The survey districts were purposively selected based on the size of the FSWs population and sociocultural regions and included Chittoor, East Godavari, Guntur, Hyderabad, Karimnagar, Prakasam, Visakhapatnam, and Warangal districts. FSWs were defined as any female, 18 years or older who had sold sex in exchange for cash at least once in the one month preceding the survey. The target sample size per district was fixed at 400 completed interviews. Data collection was done between March and October 2009.

A probability sampling method was used for selection of survey participants. Two sampling approaches were adopted following a comprehensive sampling frame development exercise spanning the entire district: (1) conventional cluster sampling was used for FSW practicing sex work at home, and in brothels, lodges, and dabhas (roadside eating establishments), where the population of FSWs was relatively stable; (2) conventional time-location cluster (TLC) sampling (dividing a site into several TLC and selecting the required number of TLCs randomly) was used for street-based FSWs.

The survey collected behavioral information and biological specimens to test for STIs including HIV. Behavioral data, including information on demographics, sex work, sexual partners, and condom use, were collected through face-toface interviews, using a pretested, precoded questionnaire translated into the local language, Telugu. Blood samples were collected for HIV and syphilis tests. Antecubital venipuncture blood sample $(5 \mathrm{~mL})$ was collected in a vacutainer, clotted for separation of serum, and stored at $2-8^{\circ} \mathrm{C}$. A $30 \mathrm{~mL}$ urine sample was collected, from which $2 \mathrm{~mL}$ was stored in a urine specimen transport tube as per the protocol of M/s GenProbe Aptima Combo 2 Assay (Gen-Probe Incorporated, USA). Sera were tested for both HIV-1 and HIV-2 by Microlisa HIV kit (J. Mitra and Co. Pvt. Ltd, India, and GENEDIA HIV 1/2 ELISA 3.0 Kit, Gencross Life Science Corporation, Korea). Syphilis reactive serology was performed by Rapid Plasma Reagin Test Kit (Span Diagnostics Ltd, India) and was confirmed by Treponema Pallidum Hemagglutination Assay (TPHA) using Syphagen TPHA Kit. All cases with RPR reactive serology of any titre with TPHA positivity were considered positive. To diagnose Neisseria gonorrhoeae and Chlamydia trachomatis, urine samples were tested using Transcription-Mediated Amplification Assay and Dual Kinetic Assay (Gen-Probe Incorporated, USA).

The study was approved by all relevant institutional review boards (Health Ministry Screening Committee, Government of India, Scientific Advisory Committee of National AIDS Research Institute, Protection of Human Subjects Committee of Family Health International and Scientific Advisory Committee, and Ethical Committee of National Institute of Nutrition). A comprehensive informed consent process was developed that allowed respondents to become fully informed and have all questions answered before agreeing to participate in the survey. Respondents were allowed to consent to the behavioral portion of the survey and opt out of the biological portion, and, once the survey process began, they could discontinue at any time. Written consent was required before the interview process could begin. Other protective measures included oaths of confidentiality by all survey staff and the development of harm minimization guidelines and specimen and data safety guidelines. The opportunity to consult with a physician and receive an STI examination, syphilis results and treatment were the major benefits for individual respondents. The survey staff also provided referrals to STI clinics and integrated testing and counseling centers. Details of the survey methodology and preliminary survey findings are available elsewhere $[6,24$, 25].

\subsection{Measures}

2.2.1. Sociodemographic Characteristics. Sociodemographic characteristics included respondent's age (in completed years), formal schooling, which was defined as their ability 
to read and write (no, yes), marital status (never married, currently married, and divorced/separated), availability of any source of income other than sex work (no, yes), typology of sex work defined as primary place or mode of solicitation (home, public places, brothel, and phone), and duration of sex work (in completed years). Typology of sex work was derived based on the primary place for engaging in sex and mode of solicitation reported by FSWs. Duration of sex work was derived as the difference between FSWs' current age and the age when they initiated paid sex.

\subsubsection{Presence and Nature of Noncommercial Partnerships.}

The two key independent variables in this study were presence of noncommercial sexual partners (no, yes) and nature of such partnerships (regular, nonregular). Presence of a noncommercial partner was measured by grouping FSWs into two categories: those who did not have a noncommercial partner and those who reported having at least one noncommercial partner at the time of survey. Commercial partners were either occasional clients (those whom FSWs did not know and recognize) or regular clients (those whom FSWs knew well and recognized). Noncommercial partners included regular partners (husband, boyfriend, and live-in partners) and nonregular partners (pimps, the police, local goon). We conceptualized nature of noncommercial partnerships (regular, nonregular) in the context of local norms and practices. It was realized that in most cases, spousal relationship may be considered to better represent regular relationships than other noncommercial partners such as boy friend or live-in partners. Hence, we defined the nature of noncommercial partnerships as regular, if FSWs reported their noncommercial regular partner as their husband (irrespective of their other sexual partnerships) and nonregular, if FSWs reported any noncommercial partner other than their husbands (e.g., boyfriend, live-in partner, pimps, the police, and local goon).

2.2.3. Outcome Indicators. The outcome indicators included in the study were inconsistent condom use with occasional and regular clients, inconsistent condom use with nonregular partners, HIV and STI status, experience of violence in the past six months (no, yes), experience of forced sex (no, yes), and practice of anal sex with commercial partners (no, yes). Inconsistent condom use was defined as failure to use a condom in every vaginal sexual encounter with a particular type of partner during the past one week. A respondent was considered HIV-positive if she tested positive for either HIV-1 or HIV-2 or both. Prevalence of the following three STIs was included syphilis, Gonorrhoeae, and Chlamydia. Experience of violence was defined as whether the FSW had been beaten by any individual in the past six months (no, yes). Experience of forced sex was defined as whether the FSW had been physically forced to have sexual intercourse with any individual in the past one year (no, yes). Practice of anal sex was defined as having anal sex with any commercial partner in the past one week (no, yes). Inconsistent condom use in anal sex was measured by failure to use a condom at last anal sex, as information on use of condoms in every anal sex encounter was not collected in the survey.

To understand the possible mechanisms by which nature of noncommercial relationships could affect FSWs' vulnerability to HIV, we examined differences in sex work characteristics and perpetrators of violence among FSWs by nature of noncommercial partnerships. Sex work characteristics which we examined were the number of days the FSW had worked as a sex worker in the past one week (0-2, $3-5,6$, or more) and the number of commercial sexual partners she had entertained in the past one week (low (05), medium (6-9), and high (10 or more)). The categorization of number of commercial sexual partners was based on the grouping adopted by India's National AIDS Control Program [2]. The information on perpetrators of violence (strangers, madams, other FSWs, paying partners, nonpaying partners, and police/pimps) was elicited among those who reported to have experienced violence in the past six months using a multiple response question.

2.3. Statistical Analyses. Cross tabulations were made to examine the differences between sociodemographic characteristics, sexual behavior, and STI/HIV prevalence among FSWs by presence and nature of noncommercial partnerships. Chi-square and unpaired $t$-tests were applied to test significance of the differences in proportions and differences in mean values, respectively. Crude odds ratios (crude OR) and adjusted odds ratios (adjusted OR) along with corresponding 95\% confidence intervals (CI) were estimated to measure the effects of the presence of noncommercial partnerships and nature of such partnerships on FSW' vulnerability to HIV and their HIV/STI status. This was done by estimating separate logistic regression models with the following binary (no, yes) outcome variables: (1) whether tested positive for HIV; (2) whether tested positive for syphilis, Gonorrhoeae, and Chlamydia (separate models for each); (3) whether used condoms inconsistently with occasional clients; (4) whether used condom inconsistently with regular clients; (5) whether experienced physical violence in the past six months; (6) whether experienced forced sex in the past 12 months; (7) whether ever had anal sex; (8) whether practiced anal sex in the past seven days; and (9) nonuse of condom at last anal sex. The crude OR were estimated by keeping only one of the two key independent variables (i.e., presence of any noncommercial partner, nature of noncommercial partnerships) as an explanatory variable in the logistic regression model, whereas the adjusted OR was computed by controlling for the effects of sociodemographic characteristics described previously.

\section{Results}

3.1. Sociodemographic Characteristics. Of 3225 FSWs who participated in the survey, 2415 (74.8\%) reported having a noncommercial partner (regular: 1792 (55.6\%), nonregular: $623(19.3 \%)$ ) (Table 1). Compared to FSWs who did not have a noncommercial partner, a larger proportion of FSWs with noncommercial partners were younger (mean age: 30.9 years 
TABLE 1: Sociodemographic characteristics of female sex workers by presence and nature of noncommercial partnerships, Andhra Pradesh, $2009(N=3225)$.

\begin{tabular}{|c|c|c|c|c|c|c|}
\hline \multirow[b]{2}{*}{ Sociodemographic characteristics } & \multicolumn{3}{|c|}{ Presence of noncommercial partners } & \multicolumn{3}{|c|}{ Nature of noncommercial partnership } \\
\hline & $\begin{array}{c}\text { No } \\
(N=810)\end{array}$ & $\begin{array}{c}\text { Yes } \\
(N=2415)\end{array}$ & $P$ value & $\begin{array}{c}\text { Regular } \\
(N=1792)\end{array}$ & $\begin{array}{l}\text { Nonregular } \\
(N=623)\end{array}$ & $P$ value \\
\hline Age $\geq 30$ years & 58.3 & 49.7 & $<0.001$ & 44.6 & 51.4 & 0.003 \\
\hline Mean age in years (SD) & $30.9(7.9)$ & $29.8(6.4)$ & 0.012 & $29.9(6.2)$ & $29.6(6.9)$ & 0.250 \\
\hline Formal schooling & 41.2 & 40.9 & 0.878 & 37.8 & 50.1 & $<0.001$ \\
\hline \multicolumn{7}{|l|}{ Marital status } \\
\hline Never married & 23.9 & 4.3 & $<0.001$ & - & 16.8 & - \\
\hline Currently married & 20.8 & 84.6 & $<0.001$ & - & 40.3 & - \\
\hline Divorced/separated & 55.4 & 11.1 & $<0.001$ & - & 42.9 & - \\
\hline \multicolumn{7}{|l|}{ Typology of sex work } \\
\hline Home based & 17.9 & 16.6 & 0.410 & 17.5 & 14.1 & 0.057 \\
\hline Public place based & 64.6 & 65.2 & 0.737 & 64.9 & 66.0 & 0.647 \\
\hline Brothel based & 8.1 & 9.0 & 0.383 & 7.9 & 12.1 & 0.002 \\
\hline Phone based & 9.5 & 9.1 & 0.745 & 7.9 & 9.6 & 0.365 \\
\hline Mean duration of sex work (SD) & $6.6(3.7)$ & $5.2(4.6)$ & $<0.001$ & $4.9(4.1)$ & $6.1(5.2)$ & 0.002 \\
\hline No source of income other than sex work & 62.2 & 48.2 & $<0.001$ & 43.9 & 60.6 & $<0.001$ \\
\hline
\end{tabular}

SD: standard deviation.

$P$ values are obtained by comparing values for FSWs with and without noncommercial partners. Significances of the differences in percentages were tested using $Z$-test. Significances of differences in average values were tested using unpaired $t$-test.

versus 29.8 years, $P=0.012$ ) and had been working as sex worker for a shorter period (mean duration: 6.6 years versus 5.2 years, $P<0.001)$. A higher proportion of FSWs who did not have a noncommercial partner, compared to those who reported having a noncommercial partner, were not currently married (never married: $23.9 \%$ versus $4.3 \%$, $P<0.001$; divorced/separated: $55.4 \%$ versus $11.1 \%, P<$ 0.001 ) and had no source of income other than sex work (62.2\% versus $48.2 \%, P<0.001)$. Similarly, among FSWs who had noncommercial partners, a larger proportion of those in unsteady relationships had no source of income other than sex work $(60.6 \%$ versus $43.9 \%, P<0.001)$ compared to those who reported being in a steady relationship.

3.2. Prevalence of HIV, STI, Risk Behaviors, and Vulnerability Factors by Presence of Noncommercial Partnerships. HIV prevalence was found to be higher among FSWs who did not have noncommercial partners compared to those who reported a noncommercial partner (18.3\% versus $11.1 \%$, adjusted OR: 0.5, 95\% CI: 0.4-0.7) (Table 2). However, FSWs who had a noncommercial partner were more likely than others to have experienced physical violence in the past six months (25.9\% versus $18.9 \%$, adjusted OR: $1.7,95 \%$ CI: $1.4-$ $2.1)$, experienced forced sex in past 12 months (16.9\% versus $13.4 \%$, adjusted OR: $1.4,95 \%$ CI: $1.1-1.7)$, and practiced anal sex in the past one week (20.9\% versus $12.5 \%$, adjusted OR: 1.7, 95\% CI: 1.4-2.1).

3.3. Prevalence of HIV, STI, Risk Behaviors, and Vulnerability Factors by Nature of Noncommercial Partnerships. FSWs who reported having nonregular partners, compared to those who had regular partners, were more likely to have HIV $(13.1 \%$ versus $10.9 \%$, adjusted OR: $1.4,95 \% \mathrm{CI}: 1.1-1.8)$, to have syphilis (10.3\% versus $4.2 \%$, adjusted OR: 2.3 , 95\% CI: $1.6-$ $3.3)$, to practice inconsistent condom use with occasional clients (21.0\% versus $16.5 \%$, adjusted OR: 1.5, 95\% CI: $1.2-1.9)$, to have experienced physical violence in the past six months (37.4\% versus $21.9 \%$, adjusted OR: 1.5 , 95\% CI: $1.2-1.9$ ), to have experienced forced sex in the past 12 months $(25.1 \%$ versus $14.1 \%$, adjusted OR: $1.9,95 \% \mathrm{CI}: 1.5-2.4)$, and to have practiced anal sex in the past one month (30.1\% versus $17.7 \%$, adjusted OR: 1.9, 95\% CI: 1.6-2.5) (Table 3).

3.4. Sex Work Characteristics and Perpetrator of Violence by Nature of Noncommercial Partnerships. FSWs in nonregular sexual partnerships, compared to those in regular sexual partnerships, had worked more days as sex workers in the past one week (mean number of days: 4.9 versus $4.1, P=$ 0.002 ) and had more commercial partners in past one week (mean number 13.9 versus 10.3, $P<0.001$ ) (Table 4). A larger proportion of FSWs in unsteady noncommercial partnerships, compared to those who were steady relationships, reported experience of violence perpetrated by paying partners $(37.7 \%$ versus $19.1 \%, P<0.001)$ and police/pimps (15.9\% versus $7.4 \%, P=0.001)$.

\section{Discussion}

This cross-sectional study shows that despite relatively higher exposure to vulnerability factors (such as violence, forced sex, and anal sex) HIV prevalence was lower among FSWs with noncommercial partners compared to those who reported no noncommercial partners. Among the subgroup of FSWs who reported having noncommercial partners, those living with their husband were found to have lower HIV and syphilis prevalence, less exposure to vulnerability factors, and higher 
TABLE 2: Prevalence of HIV, sexually transmitted infections, risk behaviors, and vulnerability factors by presence of noncommercial partners among female sex workers, Andhra Pradesh, $2009(N=3225)$.

\begin{tabular}{|c|c|c|c|c|}
\hline \multirow{3}{*}{$\begin{array}{l}\text { Prevalence of HIV, sexually transmitted infections, risk } \\
\text { behaviors, and vulnerability factors }\end{array}$} & \multicolumn{4}{|c|}{ Presence of noncommercial partner } \\
\hline & No & Yes & Crude OR & Adjusted OR \\
\hline & $(N=810)$ & $(N=2415)$ & $(95 \% \mathrm{CI})$ & $(95 \% \mathrm{CI})$ \\
\hline HIV & 18.3 & 11.5 & $0.6(0.5-0.7)$ & $0.5(0.4-0.7)$ \\
\hline Syphilis & 7.2 & 5.8 & $0.8(0.6-1.1)$ & $1.0(0.7-1.4)$ \\
\hline Neisseria gonorrhoeae & 3.0 & 2.7 & $0.9(0.5-1.4)$ & $0.7(0.5-1.2)$ \\
\hline Chlamydia trachomatis & 4.0 & 3.3 & $0.8(0.6-1.3)$ & $0.9(0.6-1.7)$ \\
\hline Inconsistent condom use with occasional clients & 16.0 & 17.7 & $1.1(0.9-1.4)$ & $1.1(0.9-1.5)$ \\
\hline Inconsistent condom use with regular clients & 16.9 & 17.8 & $1.1(0.8-1.4)$ & $1.1(0.8-1.3)$ \\
\hline Experience of physical violence, past 6 months & 18.9 & 25.9 & $1.5(1.2-1.8)$ & $1.7(1.4-2.1)$ \\
\hline Experience of forced sex, past 12 months & 13.4 & 16.9 & $1.3(1.1-1.7)$ & $1.4(1.1-1.7)$ \\
\hline Ever had anal sex & 18.5 & 26.1 & $1.6(1.3-1.9)$ & $1.5(1.2-1.9)$ \\
\hline Practice of anal sex, past one week & 12.5 & 20.9 & $1.9(1.5-2.3)$ & $1.7(1.4-2.1)$ \\
\hline No condom use in last anal sex & 7.8 & 8.2 & $1.0(0.4-2.1)$ & $0.7(0.4-1.5)$ \\
\hline
\end{tabular}

OR: odds ratio; CI: confidence interval.

FSWs who reported not having noncommercial partners were considered as reference category for computing crude and adjusted odds ratios.

Odds ratios were adjusted for FSWs' current age (in completed years), formal schooling (no, yes), typology of sex work (home, brothel/lodge, street, and phone), marital status (never married, currently married, and divorced/separated), source of income other sex work (no, yes), and duration of working as sex worker (in completed years).

TABle 3: Prevalence of HIV, sexually transmitted infections, risk behaviors, and vulnerability factors by nature of noncommercial Partnerships, Andhra pradesh, $2009(N=2415)$.

\begin{tabular}{|c|c|c|c|c|}
\hline \multirow[b]{2}{*}{$\begin{array}{l}\text { Prevalence of HIV, sexually transmitted infections, risk } \\
\text { behaviors, and vulnerability factors }\end{array}$} & \multicolumn{4}{|c|}{ Nature of noncommercial partnerships } \\
\hline & $\begin{array}{c}\text { Regular } \\
(N=1792)\end{array}$ & $\begin{array}{c}\text { Nonregular } \\
(N=623)\end{array}$ & $\begin{array}{c}\text { Crude OR } \\
(95 \% \mathrm{CI})\end{array}$ & $\begin{array}{c}\text { Adjusted OR } \\
(95 \% \mathrm{CI})\end{array}$ \\
\hline HIV & 10.9 & 13.1 & $1.2(0.9-1.6)$ & $1.4(1.1-1.8)$ \\
\hline Syphilis & 4.2 & 10.3 & $2.6(1.9-3.7)$ & $2.3(1.6-3.3)$ \\
\hline Neisseria gonorrhoeae & 2.3 & 2.8 & $0.8(0.4-1.5)$ & $0.9(0.5-1.7)$ \\
\hline Chlamydia trachomatis & 4.3 & 3.0 & $1.5(0.9-2.3)$ & $1.3(0.8-2.2)$ \\
\hline Inconsistent condom use with occasional clients & 16.5 & 21.0 & $1.3(1.1-1.8)$ & $1.5(1.2-1.9)$ \\
\hline Inconsistent condom use with regular clients & 17.5 & 18.6 & $1.1(0.8-1.4)$ & $1.1(0.9-1.5)$ \\
\hline Experience of physical violence, past 6 months & 21.9 & 37.4 & $2.1(1.7-2.6)$ & $1.9(1.5-2.3)$ \\
\hline Experience of forced sex, past 12 months & 14.1 & 25.1 & $2.0(1.6-2.6)$ & $1.9(1.5-2.4)$ \\
\hline Ever had anal sex & 22.2 & 35.2 & $1.9(1.5-2.3)$ & $1.9(1.6-2.4)$ \\
\hline Practice of anal sex, past one week & 17.7 & 30.1 & $1.9(1.6-2.5)$ & $2.1(1.7-2.6)$ \\
\hline No condom use in last anal sex & 8.4 & 8.0 & $0.9(0.5-1.7)$ & $1.1(0.5-2.1)$ \\
\hline
\end{tabular}

OR: odds ratio; $\mathrm{CI}$ : confidence interval.

Analyses were restricted among FSWs who reported having any noncommercial partner.

FSWs with regular partners were considered as reference category for computing crude and adjusted odds ratios.

Odds ratios were adjusted for FSWs' current age (in completed years), formal schooling (no, yes), typology of sex work (home, brothel/lodge, street, and phone), marital status (never married, currently married, and divorced/separated), source of income other sex work (no, yes), and duration of working as sex worker (in completed years).

condom use in commercial sex encounters compared to those who reported having nonregular partnerships with partners such as boyfriends, live-in partners, pimps, the police, and local goon.

The study finding that FSWs who only have commercial partners are most at risk for HIV and syphilis corroborates results of earlier studies that FSW' commercial sexual partnerships contribute greatly to the HIV epidemic in India
[26-28]. The higher HIV vulnerability of FSWs who were in nonregular partnerships compared to those who were in regular partnerships suggests that nature noncommercial relationships may have different effects on FSWs' vulnerability to HIV. Living with one's husband-who is a socially accepted steady noncommercial sexual partner-appears to safeguard FSWs from violence, forced sex, and risky sexual practices such as inconsistent condom use in commercial sex 
TABLE 4: Sex work characteristics and perpetrator of violence by nature of noncommercial partnerships among female sex workers, Andhra Pradesh, 2009.

\begin{tabular}{|c|c|c|c|}
\hline \multirow{2}{*}{$\begin{array}{l}\text { Sex work characteristics } \\
\text { and perpetrator of } \\
\text { violence }\end{array}$} & \multicolumn{3}{|c|}{ Nature of noncommercial partnerships } \\
\hline & $\begin{array}{c}\text { Regular } \\
(N=1792)\end{array}$ & $\begin{array}{l}\text { Nonregular } \\
(N=623)\end{array}$ & $P$ value \\
\hline \multicolumn{4}{|l|}{$\begin{array}{l}\text { Number of days worked } \\
\text { as sex worker in past one } \\
\text { week }\end{array}$} \\
\hline Up to 2 & 13.1 & 7.2 & $<0.001$ \\
\hline $3-5$ & 68.4 & 56.1 & $<0.001$ \\
\hline 6 or more & 18.6 & 36.7 & $<0.001$ \\
\hline $\begin{array}{l}\text { Mean number of days } \\
\text { (SD) }\end{array}$ & $4.1(1.5)$ & $4.9(1.6)$ & 0.002 \\
\hline \multicolumn{4}{|l|}{$\begin{array}{l}\text { Number of commercial } \\
\text { partners in past one } \\
\text { week }\end{array}$} \\
\hline Low (Up to 5$)$ & 18.2 & 9.0 & $<0.001$ \\
\hline Medium (6-9) & 32.8 & 26.3 & 0.003 \\
\hline High (10 or more) & 49.0 & 64.7 & $<0.001$ \\
\hline $\begin{array}{l}\text { Mean number of } \\
\text { clients (SD) }\end{array}$ & $10.3(6.3)$ & $13.9(9.0)$ & $<0.001$ \\
\hline $\begin{array}{l}\text { Perpetrator of violence } \\
\text { in past six months* }\end{array}$ & $(N=393)$ & $(N=233)$ & \\
\hline Strangers & 40.3 & 43.7 & 0.404 \\
\hline Madam & 2.7 & 5.2 & 0.086 \\
\hline $\begin{array}{l}\text { Other female sex } \\
\text { workers }\end{array}$ & 17.3 & 6.3 & 0.001 \\
\hline $\begin{array}{l}\text { Commercial sex } \\
\text { partners }\end{array}$ & 19.1 & 37.7 & $<0.001$ \\
\hline Nonpaying partners & 25.6 & 20.5 & 0.147 \\
\hline Police/Pimps & 7.4 & 15.9 & 0.001 \\
\hline
\end{tabular}

SD: standard deviation.

Analyses were restricted among FSWs who reported having any noncommercial partner.

* Among FSWs who reported to have experienced violence in past six months.

$P$ values are obtained by comparing values for FSWs with regular and nonregular noncommercial partners. Significances of the differences in percentages were tested using $Z$-test. Significances of differences in average values were tested using unpaired $t$-test.

and anal sex. A possible mechanism by which living with one's husband may affect FSWs is by making FSWs less dependent on sex work for their income, as seen in the finding that FSWs living with their husband reported spending fewer days engaged in sex work and entertaining fewer commercial sex partners compared to other FSWs. Another possible positive effect of FSWs living with their husband could be the involvement of such FSWs in nonsex work-related economic activities (e.g., selling vegetables/fruits or working as daily laborer), to get greater autonomy and freedom for mobility. Even if FSWs get involved in any economic activity just for sake of keeping themselves "good" in the eyes of families and society, the additional income may also reduce their economic dependency on sex work.
Studies have documented that greater economic dependence on sex work increases FSW' vulnerability to HIV $[11,14,29]$. In contrast, lesser dependence on sex work may allow FSWs greater flexibility and autonomy in negotiating for condom use with commercial partners as well as avoiding interaction with troublesome clients (e.g., those who are drunk). This was reflected, at least to some extent, by the smaller proportion of FSWs living with their husbands who experienced violence perpetrated by commercial sex partners and police/pimps compared to those who reported other men as noncommercial partners. While we recognize that low condom use in noncommercial partnerships including with husbands is an important concern for HIV prevention programs, this study indicates the possible positive health benefits of living with one's husband-an indicator of a regular noncommercial sexual partnership.

The results of this study need to be interpreted with an understanding that adding more number of partners may apparently increase the probability of being exposed to vulnerability factors such as violence, forced sex, and anal sex. Hence, we found higher proportion of FSWs reporting such factors among those who had noncommercial partners compared to those who only had commercial partners. However, the key message of this study is that among the subgroup of FSWs who had noncommercial partners, living with one's husband may bring some desirable changes in FSWs' adoption of safe sex behaviors. It has been observed that in India, most often husbands are not aware of their spouse's involvement in sex work, while other noncommercial partners are often actively involved in the management of their partner's sex work $[9,30]$. As a result, husbands are often not reached by HIV prevention programs [30]. Findings from this study suggest that HIV prevention programs should work with FSWs' having noncommercial partners such as those pimps, local goon, and the police in order to further reduce the "ping-pong" HIV transmission between them.

Although the current research provides important insights to support better HIV prevention efforts for FSWs, the findings must be interpreted with caution. We considered spousal relationships to be a better indicator of regular sexual partnership, which implies the social, economic, psychological, and physical interdependences of both partners. Although there could be few cases where FSWs may find the previous characteristics in relationships with men other than their husband, such cases are likely to be too small to affect the conclusions of this study considering the local social and cultural context. Also, the HIV status of a FSW may affect her noncommercial relationships because those HIV positive FSWs are likely to be deserted by their noncommercial partners if her HIV status is known to them. Finally, the results are based on self-reports, and effects of social-desirability bias cannot be denied.

\section{Conclusions}

In conclusion, the study results show that although FSWs who only have commercial sex partnerships have the highest burden of HIV, vulnerability to HIV is significantly higher 
among those who have noncommercial partnerships, particularly those who are in nonregular sexual partnerships. HIV prevention efforts should continue to focus on FSWs' commercial sex partnerships; however, at the same time, FSWs' nonregular sexual partnerships should also be the focus of programs with equal intensity and importance. Finally, we do not intend to suggest that concerns regarding low consistent condom use with regular noncommercial partners are less important. Rather, we intend to highlight possible positive mechanisms associated with regular sexual relationships to less risk taking as compared to nonregular sexual relationships. It is important therefore to strengthen the HIV prevention interventions with FSWs in promoting safe sexual behaviors in all sexual relationships, including those in regular and nonregular relationships.

\section{Acknowledgments}

This paper was written as part of a mentorship program under the Knowledge Network Project of the Population Council, which is a grantee of the Bill and Melinda Gates Foundation through Avahan, its India AIDS Initiative. The views expressed herein are those of the authors and do not necessarily reflect the official policy or position of the Bill and Melinda Gates Foundation and Avahan.

\section{References}

[1] National AIDS Control Organization, Press Release: HIV declining in India, New infections reduced by $50 \%$ from $2000-$ 2009, Sustained focus on prevention required, Ministry of Health \& Family Welfare, Government of India, New Delhi, India, 2010.

[2] National AIDS Control Organization (NACO), NACP-III-To halt and reverse the HIV epidemic in India. Ministry of Health \& Family Welfare, Government of India, New Delhi, India, 2006.

[3] National AIDS Control Organization (NACO), Ministry of Health \& Family Welfare, Government of India, National Behavioral Surveillance Survey, Female sex workers and clients of female sex workers, New Delhi, India, 2006.

[4] UNAIDS, Report on the global AIDS epidemic, 2008.

[5] P. Chandrasekaran, G. Dallabetta, V. Loo, S. Rao, H. Gayle, and A. Alexander, "Containing HIV/AIDS in India: the unfinished agenda," Lancet Infectious Diseases, vol. 6, no. 8, pp. 508-521, 2006.

[6] H. K. Rachakulla, V. Kodavalla, H. Rajkumar et al., "Condom use and prevalence of syphilis and HIV among female sex workers in Andhra Pradesh, India-following a large-scale HIV prevention intervention," BMC Public Health, vol. 11, supplement 6, article S1, 2011.

[7] J. T. Erausquin, M. Biradavolu, E. Reed, R. Burroway, and K. M. Blankenship, "Trends in condom use among female sex workers in Andhra Pradesh, India: the impact of a community mobilisation intervention," Epidemiol Community Health, vol. 66, no. 2, supplement, pp. ii49-ii54, 2012.

[8] M. Pickles, A. M. Foss, P. Vickerman et al., "Interim modelling analysis to validate reported increases in condom use and assess HIV infections averted among female sex workers and clients in southern India following a targeted HIV prevention programme," Sexually Transmitted Infections, vol. 86, no. 1, pp. i33-i43, 2010.

[9] K. N. Deering, P. Bhattacharjee, J. Bradley et al., "Condom use within non-commercial partnerships of female sex workers in southern India," BMC Public Health, vol. 11, supplement 6, article S11, 2011.

[10] S. Reza-Paul, T. Beattie, H. U. R. Syed et al., "Declines in risk behaviour and sexually transmitted infection prevalence following a community-led HIV preventive intervention among female sex workers in Mysore, India," AIDS, vol. 22, no. 5, pp. S91-S100, 2008.

[11] K. M. Blankenship, B. S. West, T. S. Kershaw, and M. R. Biradavolu, "Power, community mobilization, and condom use practices among female sex workers in Andhra Pradesh, India," AIDS, vol. 22, supplement 5, pp. S109-S116, 2008.

[12] B. M. Ramesh, T. S. H. Beattie, I. Shajy et al., "Changes in risk behaviours and prevalence of sexually transmitted infections following HIV preventive interventions among female sex workers in five districts in Karnataka state, south India," Sexually Transmitted Infections, vol. 86, supplement 1, pp. i17i24, 2010.

[13] R. Steen, B. Vuylsteke, T. DeCoito et al., "Evidence of declining STD prevalence in a South African mining community following a core-group intervention," Sexually Transmitted Diseases, vol. 27, no. 1, pp. 1-8, 2000.

[14] E. Reed, J. Gupta, M. Biradavolu, V. Devireddy, and K. M. Blankenship, "The context of economic insecurity and its relation to violence and risk factors for HIV among female sex workers in Andhra Pradesh, India," Public Health Reports, vol. 125, no. 4, pp. 81-89, 2010.

[15] C. Evans and H. Lambert, "The limits of behaviour change theory: condom use and contexts of HIV risk in the Kolkata sex industry," Culture, Health and Sexuality, vol. 10, no. 1, pp. 27-41, 2008.

[16] M. R. Biradavolu, S. Burris, A. George, A. Jena, and K. M. Blankenship, "Can sex workers regulate police? Learning from an HIV prevention project for sex workers in southern India," Social Science and Medicine, vol. 68, no. 8, pp. 1541-1547, 2009.

[17] D. H. Cornman, S. J. Schmiege, A. Bryan, T. Joseph Benziger, and J. D. Fisher, "An information-motivation-behavioral skills (IMB) model-based HIV prevention intervention for truck drivers in India," Social Science and Medicine, vol. 64, no. 8, pp. 1572-1584, 2007.

[18] A. Pandey, R. M. Mishra, D. Sahu et al., "Heterosexual risk behaviour among long distance truck drivers in India: role of marital status," Indian Journal of Medical Research, vol. 136, pp. 44-53, 2012.

[19] R. Zhao, B. Wang, X. Fang, X. Li, and B. Stanton, "Condom use and self-efficacy among female sex workers with steady partners in China," AIDS Care, vol. 20, no. 7, pp. 782-790, 2008.

[20] L. Murray, L. Moreno, S. Rosario, J. Ellen, M. Sweat, and D. Kerrigan, "The role of relationship intimacy in consistent condom use among female sex workers and their regular paying partners in the Dominican Republic," AIDS and Behavior, vol. 11, no. 3, pp. 463-470, 2007.

[21] H. A. C. M. Voeten, O. B. Egesah, C. M. Varkevisser, and J. D. F. Habbema, "Female sex workers and unsafe sex in urban and rural Nyanza, Kenya: regular partners may contribute more to HIV transmission than clients," Tropical Medicine and International Health, vol. 12, no. 2, pp. 174-182, 2007.

[22] K. Stoebenau, M. J. Hindin, C. A. Nathanson, P. G. Rakotoarison, and V. Razafintsalama, “.... but then he became my sipa': the implications of relationship fluidity for condom use among 
women sex workers in Antananarivo, Madagascar," American Journal of Public Health, vol. 99, no. 5, pp. 811-819, 2009.

[23] D. K. S. Chan, S. F. Cheung, A. Gray, A. Ip, and B. Lee, "Identifying the psychosocial correlates of condom use by female sex workers in Hong Kong," AIDS Care, vol. 16, no. 4, pp. 530-539, 2004.

[24] T. Saidel, R. Adhikary, M. Mainkar et al., "Baseline integrated behavioural and biological assessment among most at-risk populations in six high-prevalence states of India: design and implementation challenges," AIDS, vol. 22, supplement 5, pp. S17-S34, 2008.

[25] B. M. Ramesh, S. Moses, R. Washington et al., "Determinants of HIV prevalence among female sex workers in four south Indian states: analysis of cross-sectional surveys in twenty-three districts," AIDS, vol. 22, supplement 5, pp. S35-S44, 2008.

[26] C. M. Lowndes, M. Alary, H. Meda et al., "Role of core and bridging groups in the transmission dynamics of HIV and STIs in Cotonou, Benin, West Africa," Sexually Transmitted Infections, vol. 78, supplement 1, pp. i69-i77, 2002.

[27] P. Vickerman, A. M. Foss, M. Pickles et al., "To what extent is the HIV epidemic in southern India driven by commercial sex? A modelling analysis," AIDS, vol. 24, no. 16, pp. 2563-2572, 2010.

[28] M. Alary, A. A. Jayachandran, C. M. Lowndes et al., "Ecological analysis of the association between high-risk population parameters and HIV prevalence among pregnant women enrolled in sentinel surveillance in four southern India states," Sexually Transmitted Infections, vol. 86, supplement 1, pp. i10-i16, 2010.

[29] E. Reed, J. Gupta, M. Biradavolu, V. Devireddy, and K. M. Blankenship, "The role of housing in determining HIV risk among female sex workers in Andhra Pradesh, India: considering women's life contexts," Social Science and Medicine, vol. 72, no. 5, pp. 710-716, 2011.

[30] P. Bhattacharjee, S. Isac, T. Raghavendra, and T. S M, Role of Lovers/Boyfriends in HIV Transmission Among Female Sex Workers, Karnataka Health Promotion Trust, Bengaluru, India, 2009. 


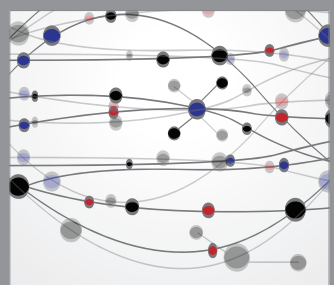

The Scientific World Journal
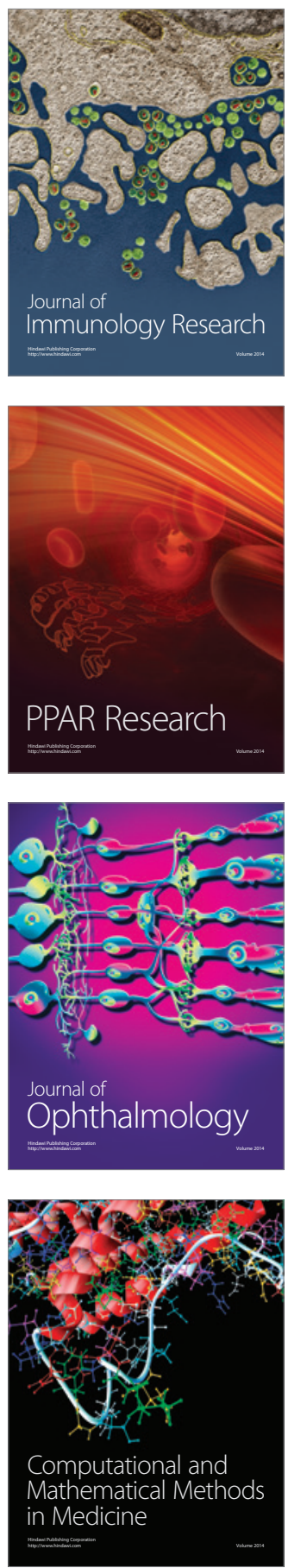

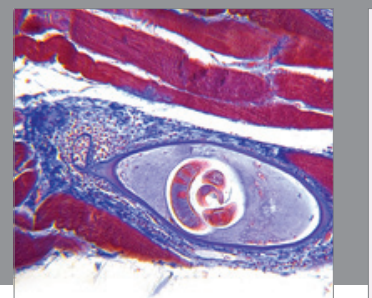

Gastroenterology

Research and Practice
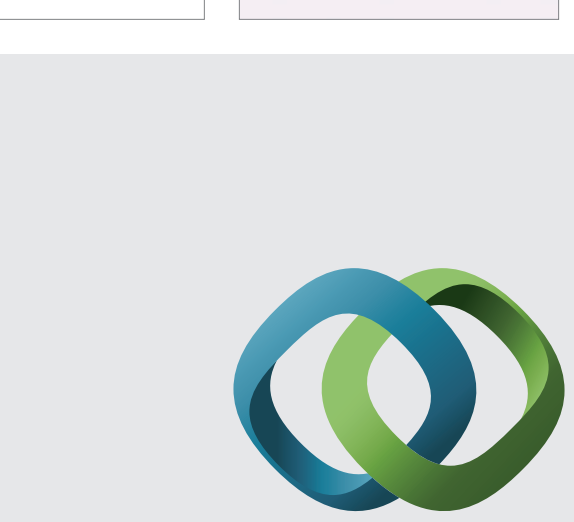

\section{Hindawi}

Submit your manuscripts at

http://www.hindawi.com
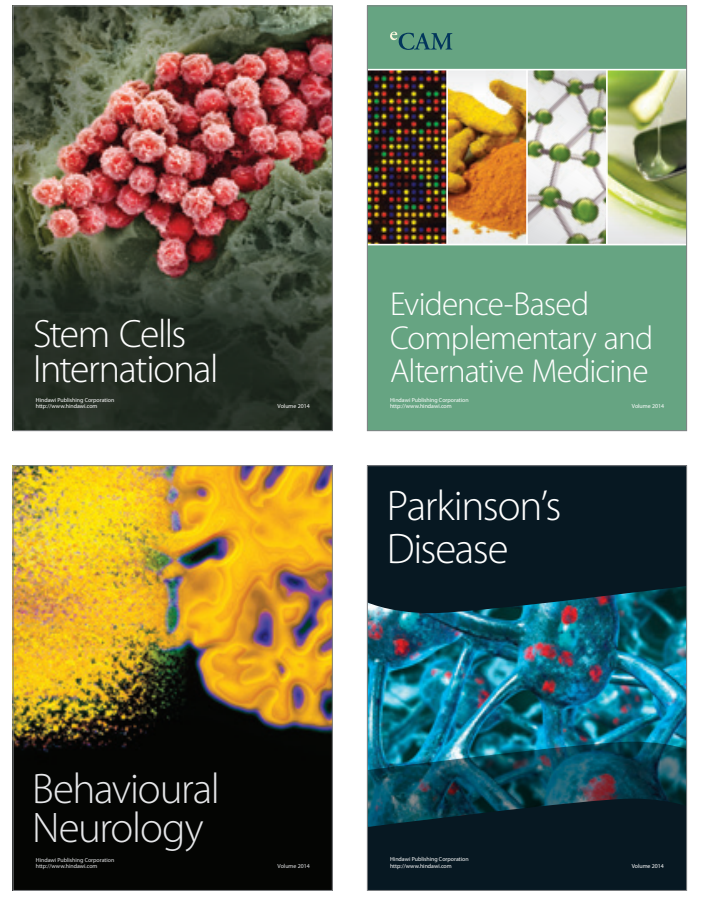
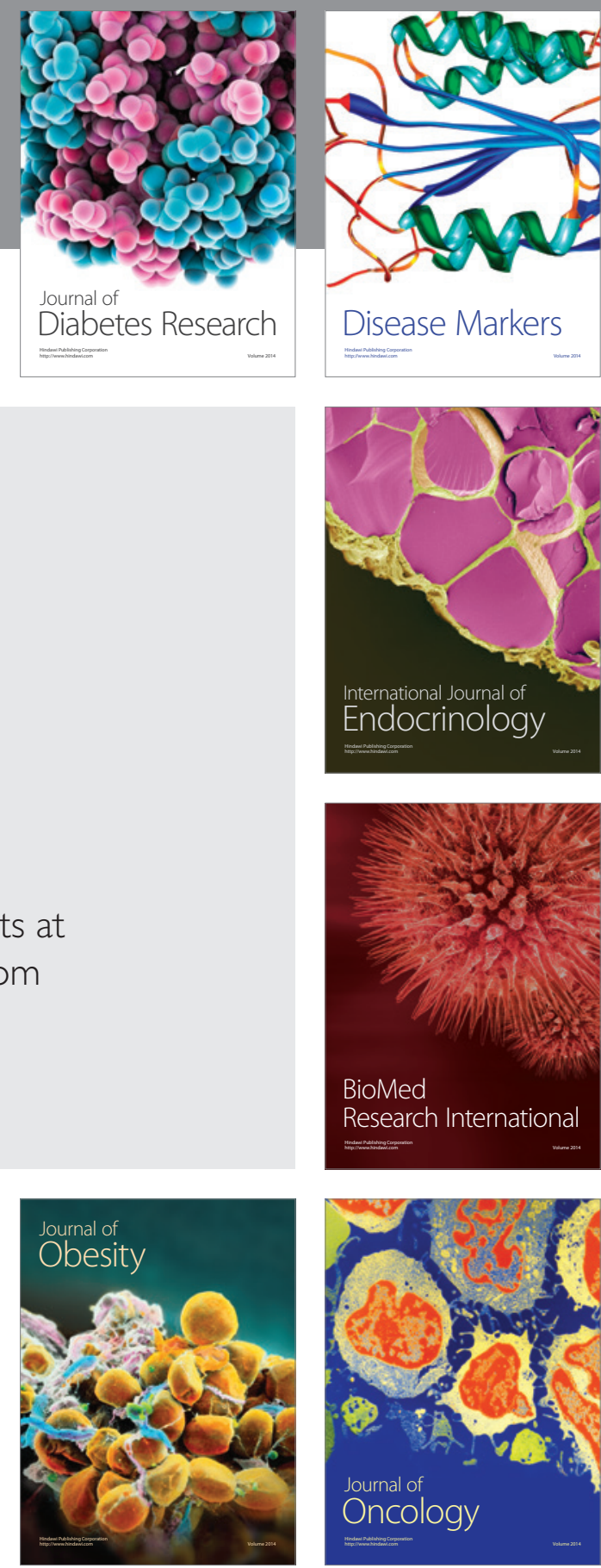

Disease Markers
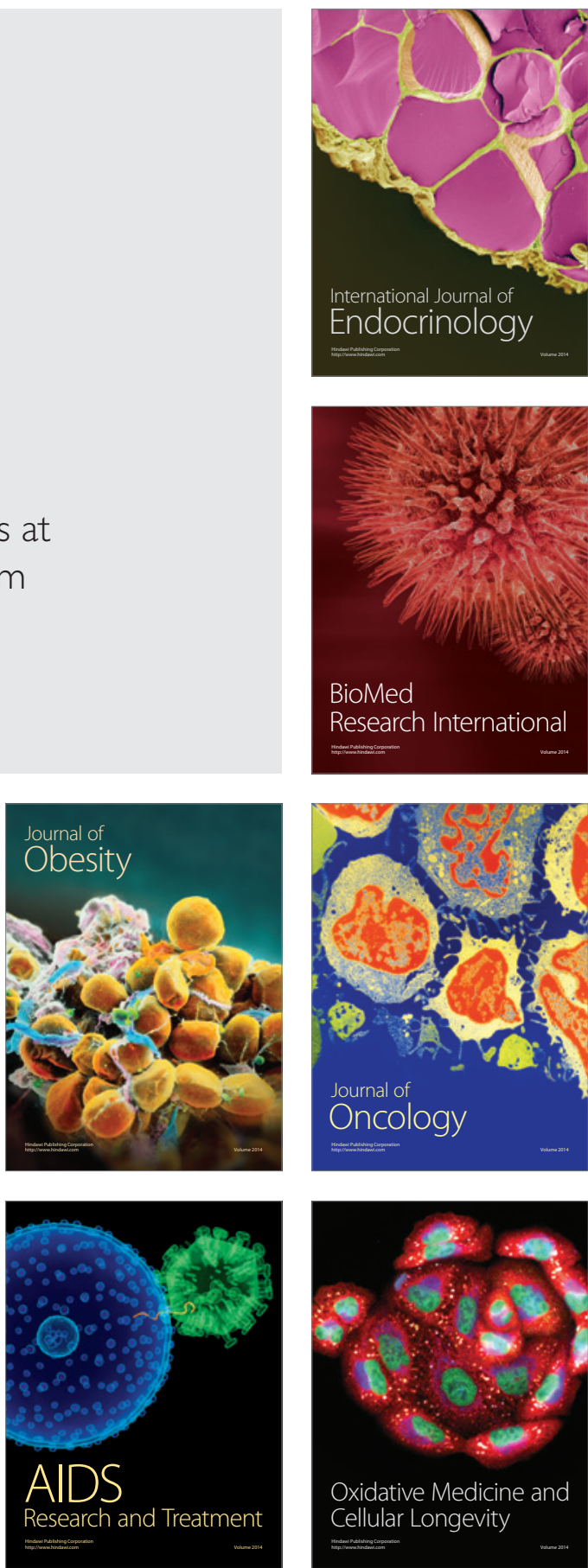